\title{
Ethnic variations regarding clinical profiles and symptom representation in prisoners with psychotic disorders
}

\author{
A. Dorina Denzel, Joke M. Harte, Mattis van den Bergh and Erik J. A. Scherder
}

\section{Background}

Black and minority ethnic (BME) groups are known to have higher prevalences of psychotic disorders and are over-represented in western penitentiaries and forensic psychiatric institutions. Research from regular mental healthcare settings suggests that they could show different and more severe psychotic symptoms.

\section{Aims}

To explore ethnic variations in severity of symptomatology of BME and non-BME detainees with psychotic disorders.

\section{Method}

In this study, 824 patients with psychotic disorders from seven different ethnic groups, imprisoned in a penitentiary psychiatric centre in the Netherlands, were compared on symptom severity and symptom representation using the BPRS-E clinical interview. Data were analysed by means of a multilevel analysis.

\section{Results}

BME patients with psychotic disorders are over-represented in forensic psychiatry, and symptom profiles of prisoners with psychotic disorders vary by ethnicity. Additionally, severity levels of overall psychopathology differ between ethnic groups: patients with an ethnic majority status show more severe levels of psychopathology compared with BME patients.

\section{Conclusions}

There are differences in symptom severity and symptom profiles between BME patients and non-BME patients. Disregarding these differences could have an adverse effect on the outcome of the treatment. Possible explanations and clinical impact are discussed.

\section{Declaration of interest}

None.

\section{Copyright and usage}

(C) The Royal College of Psychiatrists 2018. This is an Open Access article, distributed under the terms of the Creative Commons Attribution-NonCommercial-NoDerivatives licence (http://creativecommons.org/licenses/by-nc-nd/4.0/), which permits noncommercial re-use, distribution, and reproduction in any medium, provided the original work is unaltered and is properly cited. The written permission of Cambridge University Press must be obtained for commercial re-use or in order to create a derivative work.
Several studies have demonstrated that there is an over-representation of Black and minority ethnic (BME) people in western penitentiaries and forensic psychiatric institutions compared with their distribution in the general population. ${ }^{1-7}$ This could result from the finding that BME patients are especially prone to develop psychotic disorders, such as schizophrenia, compared with non-BME groups, ${ }^{7-17}$ in combination with the fact that they experience difficulties in accessing regular mental healthcare. ${ }^{1,4,18-23}$ BME patients are more often admitted compulsorily into mental healthcare and have more police involvement during the process of admittance compared with non-minority patients. ${ }^{1,4,18-23}$

In a recent systematic review, ${ }^{6}$ examining studies performed in Europe, ${ }^{1,24-31}$ the USA, ${ }^{32-40}$ Australia, ${ }^{41}$ New Zealand ${ }^{42}$ and Singapore ${ }^{43}$ on ethnic variations in psychotic disorders within the criminal justice system, it was concluded that, until now, studies have not focused on ethnic variations in psychopathology and symptom representation of adult prisoners with psychotic disorders. ${ }^{6}$ However, research in regular mental healthcare settings suggests that adult BME patients with psychotic disorders show different clinical representations ${ }^{44-47}$ and more severe psychotic symptoms. ${ }^{48,49}$ The results are inconsistent as to what specific symptoms differ between the various ethnic groups with psychotic disorders. ${ }^{21-23,25-27}$ Although the studies compare different ethnic groups on different measures of psychotic symptoms, they come to comparable conclusions: the content and severity of psychotic disorders differ between ethnic groups, disregarding these differences can negatively influence treatment outcome, and there is a need for more specific research leading to optimisation of assessment and treatment practices.

Disregarding variations in psychopathology and symptom representation may have an adverse effect on treatment outcome. ${ }^{50}$
For example, in research with patients with schizophrenia in regular mental healthcare, more severe hallucinations and delusions have been associated with worse response to treatment. ${ }^{51}$ To prevent the risk of recidivism in the already vulnerable group of (untreated) detained psychiatric patients, ${ }^{52}$ knowledge regarding differences in symptomatology between ethnic groups is essential when adequately treating forensic patients with psychotic disorders.

In the present study, we will investigate whether there are ethnic variations in clinical profiles and symptom representation between BME and non-BME persons who are currently detained in a penitentiary psychiatric centre. Firstly, we will attempt to replicate earlier findings and establish (A) whether, following the literature, BME patients in a prison setting are more often diagnosed with psychotic disorders than non-BME patients. Additionally, (B) ethnic variations in severity of psychotic disorders in detainees will be identified. Finally, (C) differences in symptom representation between $\mathrm{BME}$ and non-BME detainees with psychotic disorders will be presented.

\section{Method}

\section{Participants (the penitentiary psychiatric centres and the national database)}

Within the Dutch criminal justice system, prisoners who suffer from severe mental illness can be detained in one of the four so-called penitentiary psychiatric centres (PPC). The PPCs are established to house male and female detainees who are not able to function in a regular prison regime owing to severe psychiatric conditions. These patients are characterised by severe (auto-)aggressive, 
disruptive and/or self-destructive behaviours, as well as a high level of comorbid psychiatric, personality and substance use disorders, and often have an extensive, violent criminal history. ${ }^{50,53}$ Since May 2013, in the context of keeping track of their patient population, the PPCs have maintained a database (National Database PPCs) wherein they systematically gather data on all PPC detainees in the Netherlands to evaluate the effectiveness of treatment (routine outcome measurement) and adjust policies accordingly. To assure objectivity, data are gathered prospectively by a team of trained professionals, who work independently of the clinical staff. The database contains diagnostic information, demographic patient characteristics and criminal records, as well as information on clinical symptoms, symptom severity and the development thereof during admittance. For this study, we had the unique opportunity to obtain permission to use the data of the National Database of the PPCs for research purposes. This study includes the entire cohort of patients with psychotic disorders detained in the four PPCs in the Netherlands between 2013 and 2015. The Dutch Ministry of Security and Justice (Ministerie van Veiligheid en Justitie) authorised the usage of the data for the purpose of the current scientific research. Additionally the Ethics Committee of the Department of Law and Criminology, VU University, Amsterdam, approved this study.

\section{Measures}

\section{Psychotic disorders}

The distribution of psychotic diagnosis between patients (research question A) was investigated using a patient's DSM IV-TR diagnosis. ${ }^{21}$ Patients in the PPCs are diagnosed by clinical staff upon admittance. For this study, the diagnosis was retrieved from the patients' medical files. The following diagnostic groups were included as psychotic disorders: Schizophrenia, Disorganized Type (295.1), Schizophrenia, Catatonic Type (295.2), Schizophrenia, Paranoid Type (295.3), Schizophreniform Disorder (295.4), Schizophrenia, Residual Type (295.6), Schizoaffective Disorder (295.7), Schizophrenia, Undifferentiated Type (295.9), Delusional Disorder (297.1), Brief Psychotic Disorder (298.8) and Psychotic Disorder NOS (298.9).

\section{Symptom severity and symptom profiles}

Within the project of the National Database PPCs, the BPRS-E (Brief Psychiatric Rating Scale - Extended version) $)^{54,55}$ is used as a measure of symptom severity and symptom profiles. The BPRS$\mathrm{E}$ has been researched extensively and proven to be a sensitive instrument, and an excellent interrater reliability can be achieved with training and a standard interview procedure. ${ }^{56}$ The BPRS-E is a semi-structured interview to assess overall psychopathology during the past 2 weeks. The interview consists of 24 different psychiatric symptoms which are scored on a seven-point Likert scale ranging from 1 to 7 , with a maximum score total of 168 (see Table 1 for an overview of all BPRS-E items). High scores indicate a high level of severity. It is possible to calculate a total score of all 24 BPRS-E items to give an indication of a patient's overall symptom severity (research question B). Alternatively, to give insight into the nature of the specific psychopathology and symptom representation, the 24 items can be analysed separately (research question C), as they each represent a different symptom (see Table 1). Assessment of the BPRS-E took place within the first week of a patient's arrival at the PPC and was conducted by trained professionals working for the research team of the national database PPCs. To assure that interviewers assessed the interview in the same way, interviewers met for consensus meetings on a regular basis. Data were gathered prospectively. For this study we had permission to use data which was gathered between 2013 and 2015 .
Table 1 BPRS-E ${ }^{a}$ (Brief psychiatric rating scale - extended version)

Scoring of items based on Scoring of items based on

interview observation

Disorientation

Somatic concern

Anxiety

Depression

Suicidality

Guilt

Hostility

Elevated mood

Grandiosity

Hallucinations

Paranoia/Suspiciousness

Unusual thought content

Bizarre behaviour

Self-neglect

a. 24 items, semi-structured interview, seven-point Likert scale (1-7).

\section{Ethnicity}

For the operationalisation of ethnicity, we used the definition of Statistics Netherlands, ${ }^{57}$ wherein a person's ethnic background is established from their country of birth (first-generation immigration status for non-Dutch-born individuals) or the country of birth of a person's parents (second-generation immigration status for a Dutch-born individual). Country of birth and country of birth of parents were established by asking the participants directly. We divided participants into seven ethnic groups: the Netherlands, Morocco, Surinam, Turkey, Netherlands Antilles, other nonWestern and other Western (see Table 2 for specifications of the two residual ethnic groups). The designated groups were determined by the five largest ethnic groups in the sample, which correspond to the biggest ethnic groups in the general Dutch population, ${ }^{57}$ and two residual categories. Most of the people of Turkish and Moroccan descent immigrated to the Netherlands during the first big immigration wave of guest workers to the Netherlands in the 1960s, whereas Surinam and Netherlands Antilles belonged to the former Dutch colonies. ${ }^{58}$

A person was assigned to the residual ethnic group of other Western when descending from Europe (excluding Turkey), North America, Oceania, Indonesia or Japan ${ }^{\text {a }}$; a person descending from any other country was assigned to the group other nonWestern. By choosing these categories, we followed the definition of ethnic groups of Netherlands Statistics. ${ }^{57}$

\section{Statistical analysis}

For statistical analysis, we used the Statistical Package for the Social Sciences (SPSS, version 23). Differences in the prevalence of psychotic disorders between the seven ethnic groups, as well as differences between participants who were included and those who were excluded owing to missing values, were calculated using a chisquared test (research question A). For the analysis of ethnic differences regarding overall symptom severity (research question B) and symptom representation (research question C), BPRS-E total scores and item scores were entered in a multilevel model. A multilevel model was used because the different items of the BPRS-E are likely to be correlated within participants. Multilevel modelling allows the hierarchical structure of the data to be taken into

${ }^{a}$ Because of their socio-economic and socio-cultural positon, people from Indonesia and Japan are assigned to the group of other Western. This is based on the assumption that these people mostly descend from the former Netherlands India and employees of Japanese companies with their families (57). 
Table 2 Specification of residual ethnic groups

\begin{tabular}{|c|c|c|c|c|c|c|c|c|}
\hline \multicolumn{3}{|c|}{ Other Western country } & \multicolumn{6}{|c|}{ Other non-Western country } \\
\hline Country & $N$ & $\%$ & Country & $N$ & $\%$ & Country & $N$ & $\%$ \\
\hline Poland & 25 & 21.6 & Somalia & 27 & 18.8 & Chili & 1 & 0.7 \\
\hline Yugoslavia & 10 & 8.6 & Iraq & 11 & 7.6 & Philippines & 1 & 0.7 \\
\hline Germany & 10 & 8.5 & Dominican Republic & 7 & 4.9 & Zambia & 1 & 0.7 \\
\hline Belgium & 7 & 6.0 & Ghana & 6 & 4.2 & Côte d'Ivoire & 1 & 0.7 \\
\hline Indonesia & 7 & 6.0 & Iran & 5 & 3.5 & French Guyana & 1 & 0.7 \\
\hline Great Britain & 6 & 5.2 & Ethiopia & 5 & 3.5 & Mozambique & 1 & 0.7 \\
\hline Romania & 5 & 4.3 & Afghanistan & 5 & 3.5 & Burundi & 1 & 0.7 \\
\hline Hungary & 4 & 3.4 & Algeria & 5 & 3.5 & Rwanda & 1 & 0.7 \\
\hline Bulgaria & 4 & 3.4 & Sierra Leone & 5 & 3.5 & Jamaica & 1 & 0.7 \\
\hline Portugal & 4 & 3.4 & Angola & 4 & 2.8 & Israel & 1 & 0.7 \\
\hline United States of America & 3 & 2.6 & Brazil & 4 & 2.8 & Trinidad and Tobago & 1 & 0.7 \\
\hline Latvia & 3 & 2.6 & Cape Verde & 4 & 2.8 & Thailand & 1 & 0.7 \\
\hline Lithuania & 3 & 2.6 & South Korea & 4 & 2.8 & Kuwait & 1 & 0.7 \\
\hline Netherlands India & 3 & 2.6 & Nigeria & 3 & 2.1 & Benin & 1 & 0.7 \\
\hline Soviet Union & 3 & 2.6 & Sudan & 3 & 2.1 & Vietnam & 1 & 0.7 \\
\hline France & 2 & 1.7 & Guinea & 3 & 2.1 & Ceylon & 1 & 0.7 \\
\hline Austria & 2 & 1.7 & Lebanon & 3 & 2.1 & Central Africa & 1 & 0.7 \\
\hline Albania & 2 & 1.7 & India & 3 & 2.1 & & & \\
\hline Sweden & 2 & 1.7 & Congo & 3 & 2.1 & & & \\
\hline Greece & 2 & 1.7 & Liberia & 2 & 1.4 & & & \\
\hline Spain & 2 & 1.7 & Colombia & 2 & 1.4 & & & \\
\hline Czech Republic & 2 & 1.7 & Zaïre & 2 & 1.4 & & & \\
\hline Italy & 2 & 1.7 & Sri Lanka & 2 & 1.4 & & & \\
\hline Denmark & 1 & 0.9 & Tunisia & 1 & 0.7 & & & \\
\hline Belarus & 1 & 0.9 & Botswana & 1 & 0.7 & & & \\
\hline Estonia & 1 & 0.9 & North Yemen & 1 & 0.7 & & & \\
\hline Total & 116 & 100.0 & & & & Total & 144 & 100.0 \\
\hline
\end{tabular}

account, with observations nested within participants, and differentiates the within and between participant variance. Not taking these issues into account can lead to an increased chance of type 1 errors. $^{59}$

Owing to limited cooperation of the participants, which is often inherent to the severe psychiatric conditions of the PPC patient population, in some cases the scoring of the BPRS-E was incomplete or even not possible at all. A more traditional analysis, such as an ANOVA, would ignore all cases with even one missing value. In multilevel modelling, we do not need to reject cases with missing values altogether from the analysis. ${ }^{60}$ Under the assumption that the missing values occur random, this yields unbiased estimates of population values. We chose to exclude cases with more than ten missing values. Consequently, in this study, data from 318 participants who had ten or more missing items on the BPRS-E were excluded from the analysis.

To test ethnic differences regarding overall symptom severity, a model with the ethnic groups regressed on the BPRS-E total scores was estimated (research question B). Next, the different BPRS-E item scores and interactions between these item scores and the ethnic groups were added to the model. The improvement of these models could then be tested with likelihood ratio tests, and pairwise comparisons made to interpret the interaction.

\section{Selection of participants}

For this study, data of patients admitted to the PPCs between 2013 and 2015 were used. In this period, a total of 3831 patients were admitted to the PPCs (see Figure 1 for the inclusion of participants in the analysis). Some patients had been admitted to a PPC on more than one occasion. In that case, only the observation/measurement of the first admission per patient was used in the analysis, and 1053 duplicate observations were excluded from the analysis. Of the remaining 2778 primary cases (step 2, Figure 1), 365 patients had no legal status at the time of admittance (e.g. patients who were detained in immigration detention, but who had not committed a crime). These individuals were also excluded from the analysis. Furthermore, 109 individuals with unknown ethnicity were dropped from the analysis. One hundred and four of these were Dutch-born individuals for whom it was not possible to determine the country of birth of parents. For five individuals, country of birth, as well as country of birth of parents, was unknown. The data on the remaining 2304 patients were used to answer research question (A). To answer research question (B), of the remaining 2304 patients, we selected all 1142 (step 5, Figure 1) patients who were diagnosed with a psychotic disorder according to the DSM IV-TR criteria. ${ }^{21}$ Not included as a psychotic disorder were psychotic disorders due to substance use or psychotic disorders due a medical or somatic condition. If more than 10 out of 24 items on the BPRS-E symptom interview could not be scored owing to the limited cooperation of the patient, we judged the measurement not reliable and excluded the person from the analysis. Altogether, 318 patients were excluded from the analysis because of missing data. Finally, the data of 824 patients (step 6 in Figure 1) were used in the main analysis on overall severity of psychopathology (question B) and symptom representation (question $\mathrm{C}$ ).

\section{Results}

\section{Ethnic variations in prevalence of psychotic disorders in PPC detainees}

Before excluding participants without a psychotic disorder from the analysis (study sample at step 5 in Figure 1), we attempted to answer our first research question (A) and investigated to what extent the different ethnic groups differed regarding the prevalence of psychotic disorders (see Table 3).

Native Dutch detainees were significantly less likely to be diagnosed with a psychotic disorder (36.9\%) and were more often diagnosed with other psychiatric disorders (63.1\%), whereas all other 


\begin{tabular}{c|c|}
\hline Total No. of potential subjects \\
$(n=3831)$
\end{tabular}

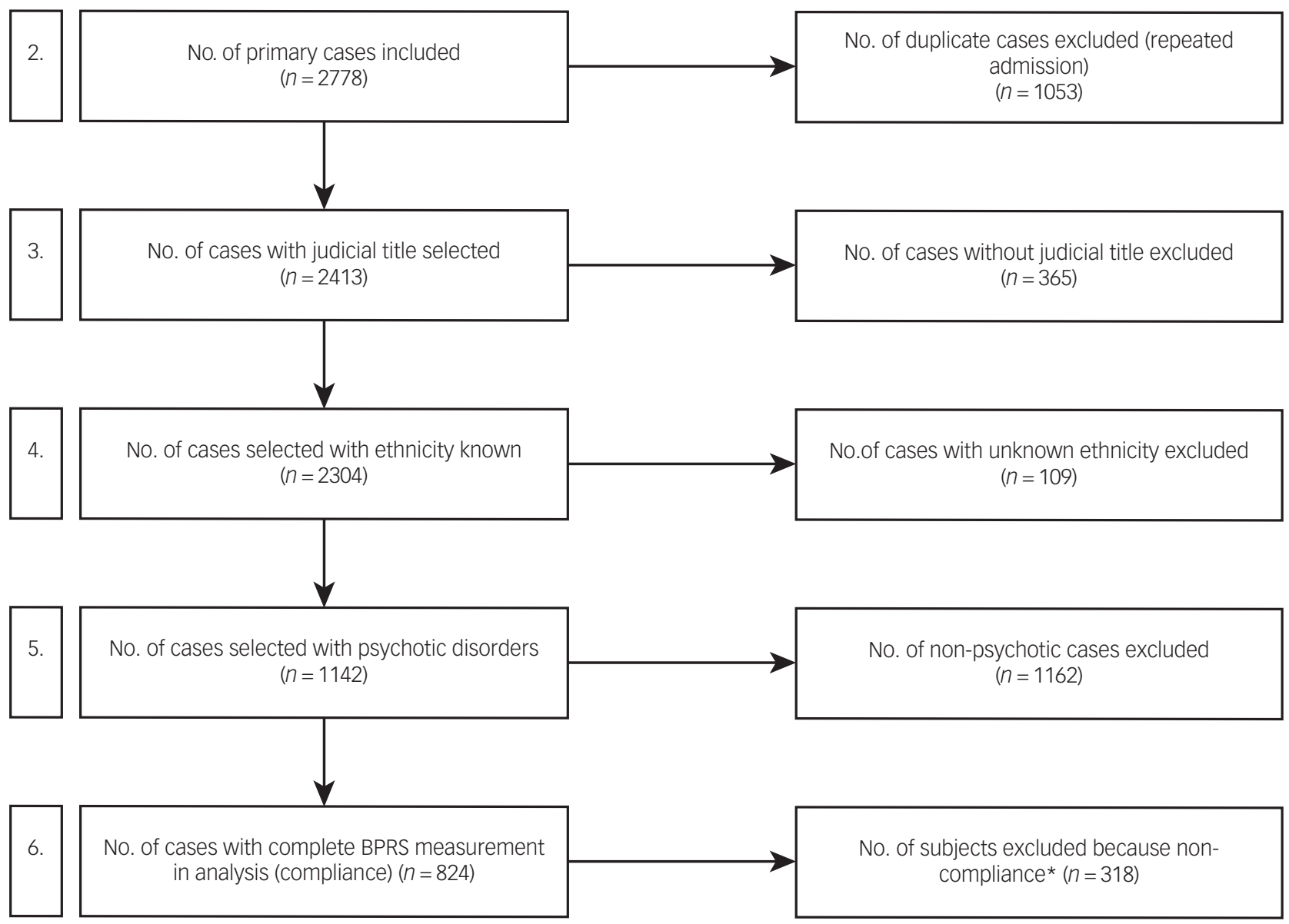

*More than 10 missing items on de BPRS interview

Fig. 1. Selection of subjects.

ethnic groups were more often diagnosed with a psychotic disorder as opposed to other disorders $\left(\mathrm{X}^{2}(6)=93.120, P<0.001\right)$.

\section{Ethnic variations in overall symptom severity in PPC detainees with psychotic disorders}

All participants without the presence of a psychotic disorder $(N=$ 1162) were excluded from further analysis. Additionally, 318 individuals with ten or more missing items on the BPRS-E interview were excluded from the analysis, as described in the Methods section (step 6 in Figure 1). Missing data from the BPRS-E interview could be due to different factors such as limited cooperation or refusal to take part in the interview, or symptomatic reasons such as disorientation of thoughts and speech. Missing data due to language barriers were prevented by using interpreters. However, the possible reasons for missing data are not specified in our data-set. To objectify possible ethnic differences, in conjunction with the BPRS interview, we analysed the distribution of ethnicity over the included and excluded participants in our sample by means of a chi-squared test (see Table 4). According to this analysis, Native

\begin{tabular}{|c|c|c|c|c|}
\hline \multirow[b]{2}{*}{ Ethnicity } & \multicolumn{2}{|c|}{ Psychotic disorder } & \multicolumn{2}{|c|}{ No psychotic disorder } \\
\hline & $N$ & $\%$ & $N$ & $\%$ \\
\hline Netherlands* & 363 & 36.9 & 622 & 63.1 \\
\hline Other non-Western & 207 & 57.0 & 156 & 43.0 \\
\hline Other Western & 180 & 52.6 & 162 & 47.4 \\
\hline Morocco & 137 & 64.3 & 76 & 35.7 \\
\hline Surinam & 119 & 67.6 & 57 & 32.4 \\
\hline Netherlands Antilles & 76 & 63.3 & 44 & 36.7 \\
\hline Turkey & 60 & 57.1 & 45 & 42.9 \\
\hline Total & 1142 & 49.6 & 1162 & 50.4 \\
\hline
\end{tabular}


Table 4 Ethnic differences between individuals included and excluded from main analysis owing to missing values on the BPRS-E

\begin{tabular}{|c|c|c|c|c|c|c|}
\hline & \multicolumn{2}{|c|}{ Included individuals } & \multicolumn{2}{|c|}{ Excluded individuals } & \multirow[b]{2}{*}{ Test statistic } & \multirow[b]{2}{*}{$P$-value } \\
\hline & N & $\%$ & N & $\%$ & & \\
\hline Total ethnicity* & 824 & 72.2 & 318 & 27.8 & $x^{2}(6)=15.267$ & 0.018 \\
\hline Netherlands* & 286 & 78.8 & 77 & 21.2 & $\varphi_{c}=0.116$ & \\
\hline Morocco & 100 & 73.0 & 37 & 27.0 & & \\
\hline Surinam & 81 & 68.1 & 38 & 31.9 & & \\
\hline Turkey & 44 & 73.3 & 16 & 26.7 & & \\
\hline Netherlands Antilles & 50 & 69.4 & 22 & 30.6 & & \\
\hline Other non-Western & 147 & 69.7 & 64 & 30.3 & & \\
\hline Other Western* & 116 & 64.4 & 64 & 35.6 & & \\
\hline
\end{tabular}

Dutch individuals had relatively high compliance rates, whereas other Western patients had relatively low compliance rates compared with the other ethnic groups. Even though the difference in compliance rates was significant, the effect size was rather small, according to Cramer's V (see Table 4 for test statistics, percentages and sample size per group). See Table 5 for descriptors, such as age and comorbidity, of the remaining 824 participants.

The likelihood ratio test showed that differences in the BPRS-E total scores were significantly explained by ethnicity (see the first two rows of Table 6). Patients of Turkish descent had the lowest total score. Native Dutch and other Western patients had a significantly higher overall score compared to Surinam, Netherlands Antillean and Turkish patients (see Table 7).

\section{Ethnic differences regarding clinical profiles and symptom representation of psychotic disorders in PPC detainees}

The next likelihood ratio tests also showed a significant improvement of the model owing to the inclusion of all the separate BPRS-E items and interaction between items and ethnic groups (Table 6).

Pairwise comparisons indicated that, of the total of 24 items (see Table 8 for mean scores and s.d.), scores on the following 13 items differed significantly between at least two of the seven ethnic groups: paranoia/suspiciousness, hostility/aggression, delusions, hallucinations, uncooperativeness, grandiosity, conceptual disorganisation, emotional withdrawal, self-neglect, bizarre behaviour, motor-hyperactivity, disorientation and suicidality.

No significant differences between the ethnic groups were found on the following 11 items (see Table 9 for mean scores and s.d.): anxiety, somatic concern, depression, blunted affect, excitement, tension, elevated mood/euphoria, feelings of guilt, distractibility, motor retardation and posturing (mannerisms). The scores of all patients were relatively high ${ }^{50}$ on anxiety and somatic concern, whereas the scores on elevated mood/euphoria, feelings of guilt, distractibility, motor retardation and posturing (mannerisms) were relatively low. Scores on depression, blunted affect, excitement and tension can be described as medium. ${ }^{50}$

In general, items that differed significantly between the groups included almost exclusively positive symptoms and symptoms of an active and aggressive nature, whereas almost all symptoms that did not vary significantly between groups described negative symptoms or symptoms with an affective component, and all patients scored relatively low on those items.

In the following, differences in symptom profiles will be described by indicating which BPRS-E item-scores of a certain ethnic group are significantly elevated compared with least one other group. Because of the large number of comparisons, we chose to describe significantly elevated scores per ethnic group. For $P$-values, test statistics and specific pair- wise comparisons between groups, see Table 8 and corresponding footnotes. Significantly lowered scores compared with other ethnic groups are reported in the footnotes of Table 8 as well. The order in which the groups are discussed is determined by sample size.

In general, the BPRS-E scores of the Dutch patients $(\boldsymbol{n}=\mathbf{2 8 6})$ were significantly elevated on eight occasions. Compared with the other ethnic groups, the symptom profile of Dutch patients was characterised by significantly higher scores on the items paranoia/ suspiciousness, delusions, hostility, uncooperativeness, grandiosity, emotional withdrawal, self-neglect and motor-hyperactivity.

The scores of patients from other non-Western countries $(\boldsymbol{n}=$ 144), the residual group composed mostly of (descendants of) refugees and asylum seekers from Africa and the Middle East, had significantly elevated scores on the BPRS-E items hallucinations, emotional withdrawal and suicidality.

The symptom profile of patients from other Western countries $(\boldsymbol{n}=\mathbf{1 1 6})$, the residual group that was composed mainly of (descendants of) guest workers from Poland and other surrounding

Table 5 Descriptive statistics of total study sample (with psychotic disorders)

$\begin{array}{lrr}\text { Variable } & \text { N } & \% \text { (s.d.) } \\ \text { Total } & 824 & 100 \\ \text { Gender } & & \\ \text { Female } & 52 & 6.3 \\ \text { Male } & 772 & 93.7 \\ \text { Mean age in years } & 36.1 & (9.8) \\ \text { Ethnicity } & & \\ \text { Netherlands } & 286 & 34.7 \\ \text { Other non-Western } & 144 & 17.6 \\ \text { Other Western } & 116 & 14.1 \\ \text { Surinam } & 81 & 9.8 \\ \text { Netherlands Antilles } & 53 & 6.4 \\ \text { Turkey } & 44 & 5.3 \\ \text { Comorbidity } & & \\ \text { Substance use disorder } & 369 & 44.8 \\ \text { Other axis I disorder } & 77 & 9.3 \\ \quad \text { Developmental disorder (ADHD, autism spectrum) } & 39 & 50.6 \\ \text { Anxiety disorder } & 18 & 23.4 \\ \text { Mood disorders } & 10 & 13.0 \\ \text { Cognitive disorders including dementia } & 3 & 3.9 \\ \quad \text { Impulse control disorders } & 2 & 2.6 \\ \text { Other disorders (e.g. adjustment, eating disorders) } & 9 & 11.7 \\ \text { Other personality disorder (PD) } & 134 & 16.3 \\ \quad \text { PD NOS } & 58 & 43.3 \\ \text { Antisocial PD } & 52 & 38.8 \\ \text { Borderline PD } & 22 & 16.4 \\ \text { Narcissistic PD } & 3 & 2.2 \\ \text { Paranoid PD } & 2 & 1.5 \\ \text { Schizotypal PD } & 2 & 1.5 \\ \text { Paranoid PD } & 2 & 1.5 \\ \text { Schizotypal PD } & 2 & 1.5 \\ \quad & & \end{array}$


Table 6 Likelihood ratio tests of ethnic groups, BPRS item scores, and the interaction between ethnic groups and BPRS item scores

\begin{tabular}{lcccrc} 
Model & -2 Log-likelihood & Number of parameters & $\Delta-2$ log-likelihood & $\Delta$ number of parameters & $P$-value \\
Null model & 73469 & 2 & & 2313 & 7 \\
+Ethnicity & 71156 & 9 & 2548 & 23 & $<0.001$ \\
+BPRS items & 68608 & 32 & 223 & 128 & $<0.001$ \\
+Ethnicity* & 68385 & 170 & & & $<0.001$ \\
BPRS items & & & & \\
\hline
\end{tabular}

European countries, was characterised by significantly high BPRS-E scores on paranoia/suspiciousness, delusions, hallucinations, grandiosity, conceptual disorganisation, self-neglect, bizarre behaviour and disorientation compared with other ethnic groups.

Moroccan patients $(\boldsymbol{n}=\mathbf{1 0 0})$ had, compared with the other groups, significantly elevated BPRS-E scores on emotional withdrawal and uncooperativeness.

The scores of patients from Surinam $(\boldsymbol{n}=\mathbf{8 1})$ were significantly higher on hostility compared with the scores of other ethnic groups.

The scores of patients from the Netherlands Antilles $(\boldsymbol{n}=\mathbf{5 3})$ were significantly higher on three items compared with other ethnic groups: paranoia/ suspiciousness, uncooperativeness and grandiosity.

Turkish patients $(n=44)$ had a significantly increased score on grandiosity compared with others.

\section{Discussion}

The aim of this study was to investigate whether (A) BME patients who are imprisoned in the PPCs are more often diagnosed with psychotic disorders than non-BME patients. In agreement with the literature from regular mental health research, prevalences of psychotic disorders varied by ethnicity: native Dutch prisoners were less often diagnosed with a psychotic disorder and more often diagnosed with other psychiatric disorders, whereas all other ethnic groups were more often diagnosed with psychotic disorders and less often with other psychiatric disorders.

Furthermore, (B) we compared ethnic variations in patients with psychotic disorders regarding overall severity level of psychopathology. This revealed that native Dutch and patients from other Western countries showed the most severe overall psychopathology compared with all other ethnic groups. As opposed to earlier research from regular mental healthcare, wherein ethnic minority status was associated with a more severe level of psychopathology, ${ }^{45,49}$ in our study with patients in crisis forensic psychiatry, ethnic majority status (native Dutch and other Western) was associated with a more severe level of psychopathology.

Finally, (C) we aimed at synthesising differences in the symptomatology of patients with psychotic disorders between the ethnic groups. The groups consisting of native Dutch, other Western and non-Western patients showed the most notable symptom representations: Native Dutch and other Western patients, the group that was composed mostly of (descendants of) guest workers from Poland

Table 7 BPRS-E mean total scores (s.d.) per ethnic group

\begin{tabular}{|c|c|}
\hline Ethnic group & Mean total BPRS-E score (s.d.) \\
\hline Other Western & $2.1(1.63)^{\star}$ \\
\hline Netherlands & $2.1(1.57)^{\star}$ \\
\hline Netherlands Antilles & $2.0(1.45)$ \\
\hline Other non-Western & $2.0(1.53)$ \\
\hline Morocco & $2.0(1.46)$ \\
\hline Surinam & $2.0(1.48)$ \\
\hline Turkey & $1.9(1.38)$ \\
\hline
\end{tabular}

and patients from other European countries, had the most serious overall symptom profile. Regarding content, native Dutch patients showed a psychotic symptom representation characterised by aggression and grandiose delusions, emotional withdrawal and hyperactivity. On the other hand, being of other Western descent was significantly associated with a regressive and disorganised profile, characterised by delusions, disorientation and bizarre behaviour, but not with aggression or uncooperativeness. This group has not been identified and studied in this context previously, and more research is needed to explain why this particular group differs so strongly from the other groups. The group of other non-Western patients, which comprised mostly (descendants of) refugees and asylum seekers from Africa and the Middle East, was characterised by symptoms of hallucinations, emotional withdrawal and suicidality. It is important to consider potential health risks of the stressful migration process in the light of recent events and the large influx of migrants from the Middle East and Africa to Europe. This is a reminder of how important accessibility of high-quality mental healthcare is in order to keep recent arrivals of refugees in Europe mentally healthy. Symptom profiles of patients from Netherlands Antilles, Morocco, Surinam and Turkey were much less severe compared with the former groups. Nevertheless, some of the findings from these groups are worth emphasising, because they differ substantially from earlier research. In contrast to previous findings in general mental healthcare, Moroccan patients in our study did not suffer from more severe overall psychopathology, nor from higher levels of hallucinations compared with native Dutch patients. ${ }^{29}$ In fact, Moroccans, who were a considerably large group in our sample, were characterised by overall lower levels of psychopathology, and only exceeded other ethnic groups regarding uncooperativeness and emotional withdrawal. Furthermore, previous studies in general mental healthcare had found high levels of hallucinations in patients originating from the Caribbean. ${ }^{44}$ However, in our sample, patients from the Netherlands Antilles were not found to be characterised by elevated levels of hallucinations. Instead, they were characterised by higher levels of delusions of grandiosity, paranoia and uncooperative behaviour. Consistent with earlier research, ${ }^{46}$ in our sample, native Dutch and other Western patients (ethnic majority groups) showed elevated levels of grandiose delusions. Yet, in the current study, Netherlands Antillean and Turkish patients showed elevations on grandiose delusions as well, which is inconsistent with earlier findings.

Furthermore, it is notable that there were no significant differences in symptom profiles observed regarding affective symptoms such as depression, anxiety, elevated mood or guilt, or negative symptoms such as blunted affect, motor retardation or mannerisms/posturing. Significant differences in symptom profiles across ethnic groups were almost exclusively observed on positive symptoms such as delusions, hallucinations, paranoia or aggression. Research has repeatedly demonstrated that positive symptoms form a risk factor for aggressive and criminal behaviour in psychotic patients, whereas negative symptoms are not associated with risk for violent behaviour in psychotic patients. ${ }^{61}$

In general, and in agreement with earlier research, we can state that BME patients in the PPCs are more often diagnosed with psychotic disorders compared with non-BME patients. ${ }^{7-17}$ Additionally, 


\begin{tabular}{|c|c|c|c|c|c|c|c|c|c|c|c|c|c|}
\hline & Paranoia & Hostility & Delusions & Hallucinations & Uncooperativeness & Grandiosity & $\begin{array}{l}\text { Conceptual } \\
\text { disorganisation }\end{array}$ & $\begin{array}{l}\text { Emotional } \\
\text { withdrawal }\end{array}$ & $\begin{array}{l}\text { Self- } \\
\text { neglect }\end{array}$ & $\begin{array}{l}\text { Bizarre } \\
\text { behaviour }\end{array}$ & $\begin{array}{l}\text { Motor- } \\
\text { hyperactivity }\end{array}$ & Disorientation & Suicidality \\
\hline \multirow[t]{2}{*}{ Other Western } & $3.3^{\star a}$ & 2.8 & $3.3^{*^{f}}$ & $2.8^{\star h}$ & 2.0 & $2.5^{\star m}$ & $2.5^{\star a}$ & 2.1 & $2.1^{\star 4}$ & $2.1^{\star W}$ & 1.7 & $1.7^{\star y}$ & 1.5 \\
\hline & 1.9 & 2.0 & 2.13 & 2.3 & 1.6 & 1.9 & 1.8 & 1.4 & 1.4 & 1.5 & 1.4 & 1.3 & 1.2 \\
\hline \multirow[t]{2}{*}{ Netherlands } & $3.5^{\star b}$ & $3.2^{\star d}$ & $3.2^{\star 8}$ & 2.5 & $2.4^{\star j}$ & $2.4^{\star n}$ & 2.0 & $2.2^{\star r}$ & $2.2^{\star v}$ & 1.9 & $1.9^{\star x}$ & 1.5 & 1.5 \\
\hline & 1.9 & 2.0 & 2.1 & 2.0 & 1.8 & 1.8 & 1.4 & 1.5 & 1.4 & 1.3 & 1.4 & 1.0 & 1.1 \\
\hline \multirow{2}{*}{$\begin{array}{l}\text { Netherlands } \\
\text { Antilles }\end{array}$} & $3.3^{\star c}$ & 3.0 & 2.7 & 2.2 & $2.7^{\star k}$ & $2.4^{\star 0}$ & 1.9 & 2.1 & 1.8 & 1.8 & 1.5 & 1.3 & 1.1 \\
\hline & 1.7 & 1.9 & 1.7 & 2.0 & 1.8 & 1.7 & 1.3 & 1.4 & 1.2 & 1.3 & 1.1 & 0.8 & 0.3 \\
\hline \multirow{2}{*}{$\begin{array}{l}\text { Other non- } \\
\text { Western }\end{array}$} & 3.1 & 2.8 & 2.7 & $3.1^{\star i}$ & 2.4 & 2.0 & 2.1 & $2.1^{* \mathrm{~S}}$ & 1.9 & 1.9 & 1.6 & 1.6 & $1.5^{\star z}$ \\
\hline & 1.9 & 2.0 & 1.9 & 2.2 & 1.7 & 1.8 & 1.5 & 1.5 & 1.1 & 1.4 & 1.1 & 1.1 & 1.4 \\
\hline \multirow[t]{2}{*}{ Morocco } & 3.2 & 3.0 & 2.6 & 2.4 & $2.5^{\star 1}$ & 1.8 & 2.0 & $2.3^{\star \mathrm{t}}$ & 1.9 & 1.7 & 1.7 & 1.4 & 1.3 \\
\hline & 1.8 & 2.1 & 1.9 & 2.0 & 1.7 & 1.4 & 1.5 & 1.4 & 1.1 & 1.0 & 1.3 & 0.9 & 1.0 \\
\hline \multirow[t]{2}{*}{ Surinam } & 3.0 & $3.3^{\star \mathrm{e}}$ & 2.5 & 2.5 & 2.0 & 2.0 & 2.0 & 1.8 & 1.7 & 1.8 & 1.6 & 1.3 & 1.2 \\
\hline & 1.8 & 2.0 & 1.9 & 2.2 & 1.6 & 1.7 & 1.5 & 1.3 & 1.2 & 1.2 & 1.3 & 0.8 & 0.6 \\
\hline \multirow{2}{*}{ Turkey } & 2.7 & 2.5 & 2.3 & 2.3 & 2.2 & $2.3^{\star \mathrm{P}}$ & 1.8 & 1.6 & 1.9 & 1.6 & 1.7 & 1.3 & 1.5 \\
\hline & 1.7 & 1.7 & 1.8 & 1.9 & 1.6 & 1.8 & 1.2 & 0.9 & 1.2 & 1.2 & 1.2 & 0.5 & 1.1 \\
\hline \multicolumn{14}{|c|}{ 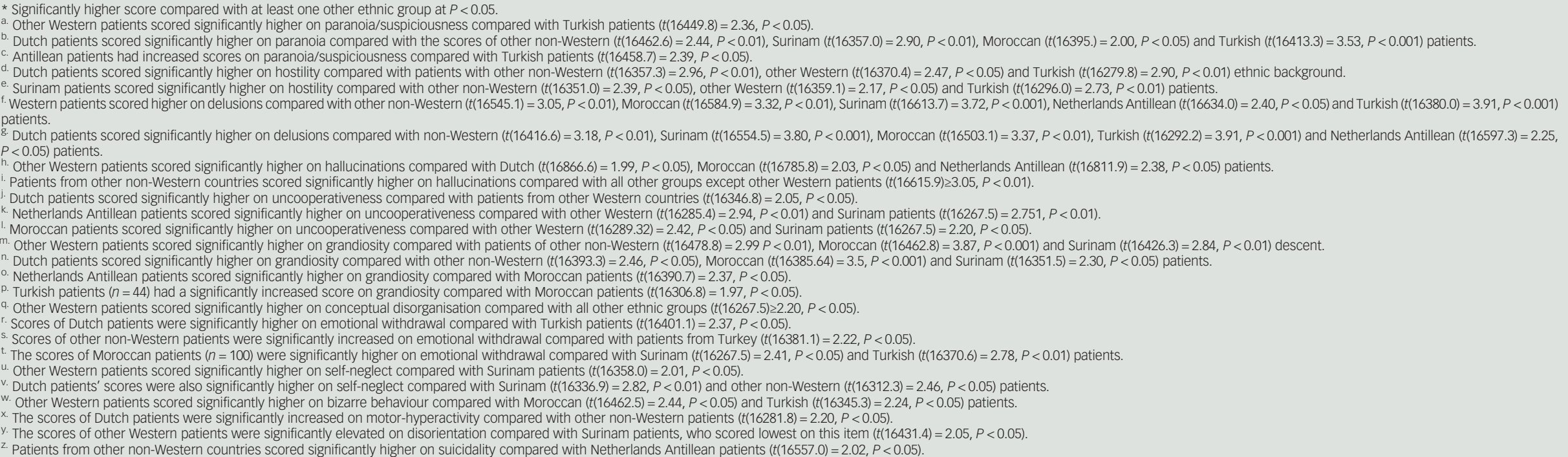 } \\
\hline
\end{tabular}


overall psychopathology and symptom profiles seemed to be more complex and more severe for ethnic majority groups (e.g. native Dutch and other Western), whereas BME patients showed less severe overall psychopathology and less complex symptom profiles, which is inconsistent with previous findings from regular mental healthcare.

The question arises why our findings differ from earlier research. Reasoning from our results, it seems that BME patients in our sample are admitted to a relatively extreme 'last resort' setting of mental healthcare, with relatively less severe overall psychopathology. Yet, regarding content, most of these groups showed elevations in paranoia and uncooperativeness.

Because the current study is based on cross-sectional data from a convenience sample, and does not contain information on prior contacts with mental healthcare, conclusions on causality or the direction thereof should be drawn with great caution. Therefore, we can only speculate about the meaning of or results in the context of earlier findings. We know that BME patients with psychotic disorders experience difficulties finding their way into regular mental healthcare: they are more often admitted compulsorily into mental healthcare and have more police involvement during the process of admittance compared with non-minority patients. ${ }^{1,4,18-23}$ In a recent systematic review, it was hypothesised that instead of being admitted into regular mental healthcare at an earlier point in their pathogenesis, BME patients seem to be criminalised more often. ${ }^{6}$ A possible reason as to why BME patients have difficulties entering regular mental healthcare in the first place could be rooted in institutionalised barriers to care cross-culturally. ${ }^{42}$ Higher levels of paranoia could also invoke higher levels of mistrust towards mental healthcare, and high levels of uncooperativeness and aggression could imply that these patients are less likely to cooperate in treatment on a voluntary basis.

As mentioned above, because of the cross-sectional nature of the current study, these hypotheses are highly speculative and future research is needed to confirm our findings and generate a solid theoretical explanation. Nevertheless, the fact that the results on symptom profiles of the current study differ from the findings of earlier research in regular mental healthcare might be explained by the absence of BME patients in regular mental healthcare and, consequently, their absence in the studies carried out in regular mental healthcare.

\section{Strengths, limitations and future directions}

To our knowledge, this is the first study to compare symptom representation and symptom severity of adult prisoners with psychotic disorders between different ethnic groups.

The results of this study are considerably strengthened by our large sample size. As the study sample is a convenience sample of imprisoned psychiatric patients, it comprises information on the entire population of forensic psychiatric patients in the Netherlands imprisoned between 2013 and 2015. By using multilevel modelling, we were able to limit the exclusion of participants due to missing values. This requires the assumption of missing values occurring at random. However, this assumption might not hold, as we found small ethnic differences between the included and excluded individuals in our study. On the other hand, other Western patients, who had the lowest compliance rate, had the highest scores on the BPRS-E overall. As limited cooperation is often inherent to the severe psychiatric condition of the PPC patient population, less compliance in a psychotic subgroup with more severe psychotic symptoms does not seem extraordinary. Even though the BME groups in our sample appeared to have less severe psychopathology overall, compared with the ethnic majority groups, most of the BME patients showed elevations on paranoia 
and uncooperativeness. The high rates of paranoia and uncooperativeness found in most BME groups in our sample could have caused higher rates of non-compliance in these groups. Consequently, it can be expected that our results would have been stronger, but similar regarding direction, if we had been able to include the missing individuals. Nevertheless, these or other factors could have biased our results, and future research is needed to see whether the current results are replicable. Furthermore, we used a clinical interview, conducted by trained professionals, to obtain data on symptomatology. This, in turn, yields more valid data than self-report questionnaires would have done. Yet, even when conducting clinical interviews to obtain data, there are potential biases that need to be addressed, especially when working with an ethnically diverse sample. Previous research warns that there could be a tendency to over-diagnose psychotic disorders and simultaneously overlook mood disorders in Moroccan patients in comparison with Dutch patients, because they verbalise their symptoms differently. ${ }^{62,63}$ On the other hand, if, hypothetically, some of the BME patients in our sample had been falsely diagnosed with psychotic disorders instead of mood disorders, it could be expected that we would have found significant differences in affective symptoms such as depression, anxiety, elevated mood, or guilt, and negative symptoms such as blunted affect or motor retardation. Nevertheless, for future research we recommend following the instructions of the authors of prior studies, who suggest the use of culturally sensitive instruments. ${ }^{62,63}$

In the present study, it was not possible to take previous mental healthcare contacts into account. To be completely able to compare the severity of symptoms, it would be preferable to effectuate a firstcontact study. Performing a first-contact study, preferably with a longitudinal design, would allow researchers to make statements about the incidence rates of psychotic disorders, which tend to give more valuable information about the aetiology/pathogenesis of the certain disorder within a certain group, compared with prevalence rates. Alternatively, future research could take previous treatment contacts or even hospital admissions into account, as research has shown that pathways into care vary by ethnicity. ${ }^{1,4,18-23}$

This is the first study to attempt a comparison of symptom profiles of prisoners with psychotic disorders between different ethnic groups in a forensic setting. Comparisons were made between subgroups of imprisoned psychiatric patients. Possibly, because of the extreme setting of forensic crisis psychiatry, all of the groups in this study may have had elevated levels of psychopathology compared with patients in regular mental healthcare or the general population. Future research could add a control group of patients from regular mental healthcare.

One group which needs specific attention in future research is our residual group of other Western patients (mostly other European). Being from other Western descent was significantly associated with delusions, disorientation and bizarre behaviour, but not with aggression or uncooperativeness. This group has not been identified in this way previously. More research is needed to scrutinise the background of this specific group of patients and to explain why this particular group differs so strongly from the other groups.

To further understand ethnic diversity in clinical manifestations, future research could take cultural aspects into account more qualitatively. There are indications that the way in which certain clinical symptoms are experienced and interpreted can be dependent on an individual's cultural background. ${ }^{64,65}$ It would be worthwhile to study positive symptoms, for example, hallucinations, more specifically in terms of religious, grandiose or paranoid content. Alternatively, it would be interesting to study culturally determined explanatory models of psychotic disorders, for example, by using the cultural formulation interview of the DSM. ${ }^{66}$

\section{Clinical implications and conclusion}

Our results have a number of implications for clinical practice. To prevent criminalisation, it would be preferable if BME patients with psychotic disorders could enter regular mental healthcare at an earlier point in their pathogenesis. To address the issue of over-representation of BME patients in the criminal justice system, policy makers should focus on the development and implementation of ethnic-specific programmes within the mental healthcare system. In the current study, we found high levels of paranoia, uncooperativeness and aggression for BME patients. These elevations could mirror a general lack of trust in the (Western) mental healthcare system and, in turn, could contribute to the difficulties BME patients experience entering mental healthcare; or, vice versa, institutional barriers to care cross-culturally could invoke mistrust in mental healthcare. Owing to the cross-sectional nature of the current study, we are not able to make statements on causality. Yet, we cannot ignore that we found symptomatic elevations of paranoia, uncooperativeness and aggression in BME patients, which need to be addressed in clinical practice. Previous research suggests that ethnic minorities in mental healthcare could benefit from, for example, matching bilingual or bicultural staff to BME patients. ${ }^{67}$ Addressing problems such as language barriers, differences regarding the understanding of mental illness and treatment between patients and professionals, involving the family in the treatment process, providing information about the illness, improving professional attitudes and cultural awareness of staff, and developing educational programmes are beneficial when providing mental healthcare to migrant groups, and might help to tackle problems such as a lack of trust in (Western) mental health professionals. ${ }^{68}$

A. Dorina Denzel, MSc, Department of Clinical Neuropsychology, VU University,

Amsterdam, van der Boechorststraat 1, 1081 BT Amsterdam, the Netherlands;

Joke M. Harte, PhD, Netherlands Institute for the Study of Crime and Law Enforcement,

(NSCR); Department of Criminology, VU University Amsterdam, de Boelelaan 1105, Initium

(1A-46), $1081 \mathrm{HV}$ Amsterdam, the Netherlands; Mattis van den Bergh, PhD,

Department of Methodology and Statistics, Tilburg University, P.O. BOx 90153, 5000 LE

Tilburg, the Netherlands; Erik J. A. Scherder, Professor, Department of Clinical

Neuropsychology, VU University, Amsterdam, van der Boechorststraat 1, 1081 BT Amsterdam, the Netherlands.

Correspondence: A. Dorina Denzel, Department of Clinical Neuropsychology, VU University, Amsterdam, van der Boechorststraat 1, 1081 BT Amsterdam, the Netherlands. Email: a.d.denzel@vu.nl

First received 29 Jan 2017, final revision 15 Oct 2017, accepted 7 Nov 2017

\section{Author contributions}

A.D.D., J.H. and E.S. conceived the idea of the study. A.D.D. designed the study. A.D.D. and M.B. performed the data analysis and interpreted the results. A.D.D. is the main author of the manuscript and wrote the first draft. A.D.D., J.H., M.B. and E.S. all contributed significantly to revising the manuscript and gave final approval of the version to be published.

\section{References}

1 Vinkers DJ, de Vries SC, van Baars AWB, Mulder CL. Ethnicity and dangerousness criteria for court ordered admission to a psychiatric hospital. Soc Psychiatry Psychiatr Epidemiol 2010; 45: 22-4.

2 Leese M, Thornicroft G, Shaw J, Thomas S, Mohan R, Harty MA, et al. Ethnic differences among patients in high-security psychiatric hospitals in England. Br J Psychiatry 2006; 188: 380-5.

3 Mulder CL, Koopmans GT, Selten J-P. Emergency psychiatry, compulsory admissions and clinical presentation among immigrants to The Netherlands. Br J Psychiatry 2006; 188: 386-91. 
4 Bhui K, Stansfeld S, Hull S, Priebe S, Mole F, Feder G. Ethnic variations in pathways to and use of specialist mental health services in the UK: systematic review. Br J Psychiatry 2003; 182: 105-16.

5 Coid JW, Kahtan N, Gault S, Jarman B. Ethnic differences in admissions to secure forensic psychiatry services. Br J Psychiatry 2000; 177: 241-7.

6 Denzel AD, Van Esch AYM, Harte JM, Scherder EJA. Ethnic variations in psychotic disorders in the criminal justice system: A systematic review. Aggress Violent Behav 2016; 29: 20-9.

7 van der Stoep T. Culturele diversiteit in de forensische psychiatrie; Een exploratief onderzoek in Forensisch Psychiatrisch Centrum de Oostvaarderskliniek. Tijdschr Psychiatr 2016; 12: 846-53.

8 Dealberto M-J. Ethnic origin and increased risk for schizophrenia in immigrants to countries of recent and longstanding immigration. Acta Psychiatr Scand 2010; 121: 325-39

9 Bresnahan M, Begg MD, Brown A, Schaefer C, Sohler N, Insel B, et al. Race and risk of schizophrenia in a US birth cohort: Another example of health disparity? Int J Epidemiol 2007; 36: 751-8.

10 Fearon P, Kirkbride JB, Morgan C, Dazzan P, Morgan K, Lloyd T, et al. Incidence of schizophrenia and other psychoses in ethnic minority groups: Results from the MRC AESOP Study. Psychol Med 2006; 36: 1541-50.

11 Cantor-Graae E, Selten J-P. Schizophrenia and migration: A meta-analysis and review. Am J Psychiatry 2005; 162: 12-24.

12 King M, Nazroo J, Weich S, McKenzie K, Bhui K, Karlsen S, et al. Psychotic symptoms in the general population of England: A comparison of ethnic groups (The EMPIRIC study). Soc Psychiatry Psychiatr Epidemiol 2005; 40: 375-81.

13 Hutchinson G, Haasen C. Migration and schizophrenia: The challenges for European psychiatry and implications for the future. Soc Psychiatry Psychiat Epidemiol 2004; 39: 350-7.

14 Mcgrath J, Saha S, Welham J, El Saadi O, MacCauley C, Chant D, et al. A systematic review of the incidence of schizophrenia: The distribution of rates and the influence of sex, urbanicity, migrant status and methodology. BMC Med 2004; 2: 13.

15 Cantor-Graae E, Pedersen CB, MCNeil TF, Mortensen PB. Migration as a risk factor for schizophrenia: A Danish population-based cohort study. Br J Psychiatry 2003; 182: 117-22.

16 Carpenter L, Brockington IF. A study of mental illness in Asians, West Indians and Africans living in Manchester. Br J Psychiatry 1980; 137: 201-5.

17 Hollander AC, Dal H, Lewis G, Magnusson C, Kirkbride JB, Dalman C. Refugee migration and risk of schizophrenia and other non-affective psychoses: Cohort study of 1.3 million people in Sweden. BMJ. 2016; 352: i1030.

18 Alegría M, Canino G, Ríos R, Vera M, Calderón J, Rusch D, et al. Inequalities in use of specialty mental Health Services Among Latinos, African Americans, and non- Latino Whites. Psychiatr Serv 2002; 53: 1547-55.

19 Coid J, Petruckevitch A, Bebbington $\mathrm{P}$, Brugha $T$, Bhugra $\mathrm{D}$, Jenkins $\mathrm{R}$, et al. Ethnic differences in prisoners II: Risk factors and psychiatric service use? $\mathrm{Br}$ J Psychiatry 2002; 181: 481-7.

20 Leese M, Thornicroft G, Shaw J, Thomas S, Mohan R, Harty MA, et al. Ethnic differences among patients in high-security psychiatric hospitals in England. $\mathrm{Br} J$ Psychiatry 2006; 188: 380-5.

21 Lindert J, Schouler-Ocak M, Heinz A, Priebe S. Mental health, health care utilisation of migrants in Europe. Eur Psychiatry J Assoc Eur Psychiatry 2008; 23: 14 20

22 Mulder CL, Koopmans GT, Selten JP. Emergency psychiatry, compulsory admissions and clinical presentation among immigrants to The Netherlands. $\mathrm{Br} J$ Psychiatry 2006; 188: 386-91.

23 de Wit MAS, Tuinebreijer WC, van Brussel GHA, Selten J-P. Ethnic differences in risk of acute compulsory admission in Amsterdam, 1996-2005. Soc Psychiatry Psychiatr Epidemiol 2012; 47: 111-8.

24 Bhui $K$, Brown $P$, Hardie $T$, Watson JP, Parrott J. African-Caribbean men remanded to Brixton Prison: Psychiatric and forensic characteristics and outcome of final court appearance. Br J Psychiatry 1998; 172: 337-44.

25 Gabrielsen G, Kramp P. Forensic psychiatric patients among immigrants in Denmark: Diagnoses and criminality. Nord J Psychiatry 2009; 63: 140-7.

26 Vinkers DJ, Selten J-P, Hoek HW, Rinne T. Psychotic disorders are more common in ethnic minority than in Dutch native defendants. Soc Psychiatry Psychiatr Epidemiol 2013; 48: 1399-404.

27 Vinkers DJ, Barendregt M, de Beurs E, Hoek HW, Rinne T. Etnische verschillen tussen pro justitia gerapporteerde verdachten. Tijdschr Psychiatr 2011; 53 801-11.

28 Hoffmann K. Migrant patients in forensic psychiatry: An epidemiological survey from the german country of Baden-Wurttemberg (Migranten im Maßregelvollzug: Eine versorgungsepidemiologische Erhebung aus BadenWürttemberg). Nervenarzt 2006; 77: 50-7.

29 Sturup J, Kristiansson M. Severe mental disorder-difficult forensic psychiatric evaluation: Differences between swedes and immigrants and between women and men analyzed (Allvarlig psykisk störning: En svår rättspsykiatrisk bedömning). Klin och Vetensk 2007; 104: 1702-6.

30 Coid J, Ullrich S. Prisoners with psychosis in England and Wales: Diversion to psychiatric inpatient services. Int J Law Psychiatry 2011; 34: 99-108.

31 Gosden NP, Kramp P, Gabrielsen G, Andersen TF, SeStoft D. Mental disorders and charges of violent offences. A study of male adolescent remand prisoners. Int J Law Psychiatry 2006; 29: 186-94.

32 Linhorst DM, Hunsucker L, Parker LD. An examination of gender and racial differences among Missouri insanity acquittees. J Am Acad Psychiatry Law 1998; 26: 411-24.

33 Paradis CM, Horn L, Yang CM, O'Rourke T. Ethnic differences in assessment and treatment of affective disorders in a jail population. J Offender Rehabil 1999; 28: 23-32.

34 Perry BL, Neltner M, Allen T. A paradox of bias: racial differences in forensic psychiatric diagnosis and determinations of criminal responsibility. Race Soc Probl 2013; 5: 239-49.

35 Toch H, Adams K, Greene R. Ethnicity, disruptiveness, and emotional disorder among prison inmates. Crim Justice Behav 1987; 14: 93-109.

36 Duncan A, Sacks S, Melnick G, Cleland CM, Pearson FS, Coen CAM. Performance of the CJDATS Co-Occurring Disorders Screening Instruments (CODSIS) among minority offenders. Behav Sci Law 2008; 26: 351-68.

37 Teplin LA. The prevalence of severe mental disorder among male urban jail detainees: Comparison with the Epidemiologic Catchment Area Program. Am J Public Health 1990; 80: 663-9.

38 Baridon PC, Rosner K. Characteristics of women forensic patients in a federal hospital. Hosp Community Psychiatry 1981; 32: 50-3.

39 Hartwell S. An examination of racial differences among mentally ill offenders in Massachusetts. Psychiatr Serv 2001; 52: 234-6.

40 Karnik NS, Soller MV, Redlich A, Silverman MA, Kraemer HC, Haapanen R, et al. Prevalence differences of psychiatric disorders among youth after nine months or more of incarceration by race/ethnicity and age. J Health Care Poor Underserved 2010; 21: 237-50.

41 Butler T, Allnutt S, Kariminia A, Cain D. Mental health status of Aboriginal and non-Aboriginal Australian prisoners. Aust N Z J Psychiatry 2007; 41: 429-35.

42 Simpson AIF, Brindred PM, Fairley N, Laidlaw TM, Malcolm F. Does ethinicity affect need for mental health services among New Zealand prisoners? Aust N Z J Psychiatry 2003; 37: 728-34.

43 Koh KGWW, Peng GK, Huak CY, Koh BKW. Migration psychosis and homicide in Singapore: A five year study. Med Sci Law 2006; 46: 248-54.

44 Johns LC, Nazroo JY, Bebbington P, Kuipers E. Occurrence of hallucinatory experiences in a community sample and ethnic variations. Br J Psychiatry 2002; 180: 174-8

45 Lim CS, Subramaniam M, Poon LY, Chong SA, Verma S. Cross-ethnic differences in severity of symptomatology of individuals with first-episode schizophrenia spectrum disorder. Early Interv Psychiatry 2011; 5: 242-8.

46 Yamada AM, Barrio C, Morrison SW, Sewell D, Jeste DV. Cross-ethnic evaluation of psychotic symptom content in hospitalized middle-aged and older adults. Gen Hosp Psychiatry 2006; 28: 161-8.

47 Barrio C, Yamada A-M, Atuel H, Hough RL, Yee S, Berthot B, et al. A tri-ethnic examination of symptom expression on the positive and negative syndrome scale in schizophrenia spectrum disorders. Schizophr Res 2003; 60: $259-69$.

48 Kennedy N, Boydell J, van Os J, Murray RM. Ethnic differences in first clinical presentation of bipolar disorder: Results from an epidemiological study. $J$ Affect Disord 2004; 83: 161-8.

49 Veling W, Selten J-P, Mackenbach JP, Hoek HW. Symptoms at first contact for psychotic disorder: comparison between native Dutch and ethnic minorities. Schizophr Res 2007; 95: 30-8.

50 van Beek J, Vuijk PJ, Harte JM, Smit BL, Nijman H, Scherder EJA. The Factor Structure of the Brief Psychiatric Rating Scale (Expanded Version) in a Sample of Forensic Psychiatric Patients. Int J Offender Ther Comp Criminol 2014; 59: 743-56.

51 Robinson DG, Woerner MG, Alvir JM, Geisler S, Koreen A, Sheitman B, et al. Predictors of treatment response from a first episode of schizophrenia or schizoaffective disorder. Am J Psychiatry 1999; 156: 544-9.

52 Lamsma J, Harte JM. Violence in psychosis: Conceptualizing its causal relationship with risk factors. Aggress Violent Behav 2015; 24: 75-82.

53 de Wilde S, Harte J, Denzel D. Psychiatrische patiënten in detentie: Het belang van etnische achtergrond. Proces 2015; 94: 148-9.

54 Lukoff $D$, Nuechterlein $H$, Ventura J. Manual for the expanded brief psychiatric rating scale. Schizophr Bull 1986; 12: 594-602.

55 Dingemans PMaJ, Linszen DH, Lenior ME, Smeets RMW. Component structure of the expanded Brief Psychiatric Rating Scale (BPRS-E). Psychopharmacology 1995; 122: 263-7. 
56 Burlingame GM, Seaman S, Johnson JE, Whipple J, Richardson E, Rees F, et al Sensitivity to change of the Brief Psychiatric Rating Scale - Extended (BPRS E): An item and subscale analysis. Psychol Serv 2006; 3: 77-87.

57 Netherlands Statistics Centraal Bureau voor de Statistiek CBS. Gedetineerden; geslacht, leeftijd en herkomstgroepering. Den Haag/Heerlen, 2015.

58 Sanderse C, Verweij A, Beer J. Migratie samengevat. In: Volksgezondheid Toekomst Verkenning. Nationaal Kompas Volksgezondheid, 2011

59 Goldstein H. Multilevel Statistical Models. John Wiley \& Sons, 2011: 922.

60 Goldstein H, McDonald RP. A general model for the analysis of multilevel data. Psychometrika 1988; 53: 455-67.

61 Witt K, Van Dorn R, Fazel S. Risk factors for violence in psychosis: Systematic review and meta-regression analysis of 110 studies. PLOS One 2013; 8: e55942.

62 Zandi T, Havenaar JM, Smits M, Limburg-Okken AG, van Es H, Cahn W, et al. First contact incidence of psychotic disorders among native Dutch and Moroccan immigrants in the Netherlands: Influence of diagnostic bias. Schizophr Res 2010; 119: 27-33.

63 Zandi T, Havenaar JM, Limburg-Okken AG, van Es H, Sidali S, van den Kadri N, et al. The need for culture sensitive diagnostic procedures: A study among psychotic patients in Morocco. Soc Psychiatry Psychiatr Epidemiol 2007; 43: 244-50.

64 Jessurun AY, Raes BCM. Een Antilliaanse psychose? Behandeling van een psychose die door de patiënt geduid wordt als zwarte magie. Tijdschr Psychiatr 2005; 47: 807-11

65 Gokoel K. Geesten of schizofrenie: Een beschrijving van een Hindoestaanse patiënt. Tijdschr Psychiatr 2005; 47: 801-5.

66 Mezzich JE, Caracci G, Fabrega H, Kirmayer L. Cultural formulation guidelines. Transcult Psychiatry 2009; 46: 383-405.

67 Akutsu PD, Snowden LR, Organista KC. Referral patterns in ethnic-specific and mainstream programs for ethnic minorities and Whites. J Couns Psycho 1996; 43: 56-64.

68 Priebe S, Sandhu S, Dias S, Gaddini A, Greacen T, Ioannidis E, et al. Good practice in health care for migrants: Views and experiences of care professionals in 16 European countries. BMC Public Health 2011; 11: 187. 